\title{
The importance of open science for biological assessment of aquatic environments
}

\author{
Marcus W Beck ${ }^{\text {Corresp., } 1,2}{ }^{2}$, Casey O'Hara ${ }^{3}$, Julia S Stewart Lowndes ${ }^{4}$, Raphael Mazor ${ }^{1}$, Susanna Theroux ${ }^{1}$, David \\ Gillett $^{1}$, Belize Lane ${ }^{5}$, Gregory Gearheart ${ }^{6}$ \\ ${ }^{1}$ Southern California Coastal Water Research Project, Costa Mesa, California, USA \\ 2 Tampa Bay Estuary Program, Saint Petersburg, Florida, USA \\ 3 Bren School of Environmental Sciences \& Management, University of California, Santa Barbara, Santa Barbara, California, United States \\ 4 National Center for Ecological Analysis and Synthesis, Santa Barbara, California, USA \\ 5 Department of Civil and Environmental Engineering, Utah Water Research Laboratory, Utah State University, Logan, Utah, United States \\ 6 California Water Resources Control Board, Sacramento, California, USA \\ Corresponding Author: Marcus W Beck \\ Email address: mbeck@tbep.org
}

Open science principles that seek to improve science can effectively bridge the gap between researchers and environmental managers. However, widespread adoption has yet to gain traction for the development and application of bioassessment products. At the core of this philosophy is the concept that research should be reproducible and transparent, in addition to having long-term value through effective data preservation and sharing. In this paper, we review core open science concepts that have recently been adopted in the ecological sciences and emphasize how adoption can benefit the field of bioassessment for both prescriptive condition assessments and proactive applications that inform environmental management. An example from the state of California demonstrates effective adoption of open science principles through data stewardship, reproducible research, and engagement of stakeholders with multimedia applications. We also discuss technical, sociocultural, and institutional challenges for adopting open science, including practical approaches for overcoming these hurdles in bioassessment applications. 


\title{
1 The importance of open science for biological 2 assessment of aquatic environments
}

3

4

5

6

\author{
Marcus W. Beck ${ }^{\text {Corresp., 1, 2, Casey O’Hara }}{ }^{3}$, Julia S. Stewart Lowndes ${ }^{4}$, Raphael D. Mazor ${ }^{1}$, \\ Susanna Theroux ${ }^{1}$, David J. Gillett ${ }^{1}$, Belize Lane ${ }^{5}$, Greg Gearheart ${ }^{6}$ \\ ${ }^{1}$ Southern California Coastal Water Research Project, 3535 Harbor Blvd, Costa Mesa, CA, \\ 92626, USA \\ 2 Tampa Bay Estuary Program (current address), $26313^{\text {th }}$ Ave S Ste 350, St. Petersburg, FL, \\ 33701, USA \\ ${ }^{3}$ Bren School of Environmental Sciences \& Management, University of California Santa \\ Barbara, 2400 Bren Hall, Santa Barbara, CA, 93117, USA \\ ${ }^{4}$ National Center for Ecological Analysis and Synthesis, 735 State St, Santa Barbara, CA, \\ 93101, USA \\ ${ }^{5}$ Department of Civil and Environmental Engineering, Utah Water Research Laboratory, Utah \\ State University, 1600 Canyon Rd, Logan, UT, 84321, USA \\ ${ }^{6}$ California State Water Resources Control Board, 1001 I Street, Sacramenta, CA, 95814, USA \\ Corresponding Author: Marcus W. Beck \\ Email address: mbeck@tbep.org
}

\section{Abstract}

Open science principles that seek to improve science can effectively bridge the gap between researchers and environmental managers. However, widespread adoption has yet to gain traction for the development and application of bioassessment products. At the core of this philosophy is the concept that research should be reproducible and transparent, in addition to having long-term value through effective data preservation and sharing. In this paper, we review core open science concepts that have recently been adopted in the ecological sciences and emphasize how adoption can benefit the field of bioassessment for both prescriptive condition assessments and proactive applications that inform environmental management. An example from the state of California demonstrates effective adoption of open science principles through data stewardship, reproducible research, and engagement of stakeholders with multimedia applications. We also discuss technical, sociocultural, and institutional challenges for adopting open science, including practical approaches for overcoming these hurdles in bioassessment applications. 


\section{Introduction}

35 Bioassessment is an essential element of aquatic monitoring programs that helps guide decisions for managing the ecological integrity of environmental resources. Legal mandates to assess biological condition have stimulated the development of bioassessment programs and tools in the United States (Clean Water Act, CWA), Canada (Canada Waters Act), Europe (Water Framework Directive), China (Environmental Quality Standards for Surface Water), South Africa (National Water Act), and elsewhere (Borja et al. 2008). Decades of research have supported the development of assessment indices for multiple assemblages with regional applications in streams, rivers, lakes, and marine environments (Karr et al. 1986, Kerans and Karr 1994, Fore and Grafe 2002, Beck and Hatch 2009, Borja et al. 2009, 2016). Substantial technical advances have been made in measuring biological responses to environmental change (Hawkins et al. 2000a, 2000b), how these responses can be distinguished from natural environmental variation (Stoddard et al. 2006, Hawkins et al. 2010), and interpreting the impacts of these changes (Davies and Jackson 2006).

Integrating bioassessment products (e.g., scoring indices, causal assessment protocols) into management or regulatory frameworks can be challenging, despite the technological advances (Kuehne et al. 2017). How a bioassessment product is used in practice to inform decisions and prioritize management actions can differ from why it may have been originally developed. Numerous assessment products have been developed for specific regional applications (Birk et al. 2012) and concerns about redundancy, comparability, duplicated effort, and lack of coordinated monitoring have recently been highlighted (Cao and Hawkins 2011, Poikane et al. 2014, Kelly et al. 2016, Nichols et al. 2016). Kuehne et al. (2019) recently highlighted a lack of institutional connectivity among actors with expertise in freshwater assessment as a hallmark of the status quo in which applied science is conducted. Moreover, existing indices may not be easily calculated by others beyond initial research applications (Hering et al. 2010, Nichols et al. 2016) or may be incorrectly applied based on differences between goals for developing an index and the needs of management programs (Dale and Beyeler 2001, Stein et al. 2009). The abundance of available products can be a point of frustration for managers given a lack of guidance for choosing among alternatives, particularly as to how different assessment products relate to specific management, monitoring, or policy objectives (Dale and Beyeler 2001, Stein et al. 2009).

To address these challenges, a new mode of operation is needed where method development is open and transparent, developed products are discoverable and reproducible, and most importantly, implementation in the management community is intuitive and purposeful. Open science principles that improve all aspects of the scientific method can help meet these needs and there is a unique opportunity in bioassessment to leverage openness to support public resources. Open science and its ideals originated partly due to failures of reproducibility and biases in the primary literature that were revealed as systematic concerns in research fields with immediate implications for human health (Makel et al. 2012, Franco et al. 2014). These ideas and the failures that they address have slowly permeated the ecological and environmental sciences (Hampton et al. 2015, 2016, Lowndes et al. 2017). Open science has also influenced how research workflows are conceptualized in other disciplines (e.g., archaeology, Marwick et al. 2016, behavioral ecology, Ihle et al. 2017, hydrology, Slater et al. 2019, vegetation sciences, Collins 2016) and has enabled a shift towards publishing structures that are more fair and 
transparent through open access (Oudenhoven et al. 2016, Essl et al. 2020). Limited examples have suggested that open access databases can be leveraged to develop bioassessment products that increase transparency among stakeholders (Borja et al. 2019). Adopting an open science paradigm in bioassessment is particularly relevant compared with other fields given the explicit need to develop products that are accessible to the management community. Legal and ethical precedents in bioassessment may also necessitate open data sharing given that environmental monitoring programs are often established to protect and maintain publicly-owned natural resources.

\section{Survey Methodology and Objectives}

This review draws on previous literature to describe approaches for open science that can empower the research and management community to embrace a new mode of thinking for bioassessment applications. These approaches are expected to benefit the bioassessment research community by providing new tools that augment existing workflows for developing assessment products and improving their ability to address environmental issues by bridging the gap between the scientific, management, and regulatory communities. The intended audience for this review is primarily the research team that develops bioassessment products, but we also write for the funders and users (e.g., regulators and managers) of these products to emphasize the value of investing in open science for the protection of public resources.

This traditional review covers literature published in recent years advocating for open science in different fields of study. Because no similar efforts have yet been made to apply these principles to bioassessment, we draw on examples from the previous literature that demonstrate successful applications in other fields to motivate researchers and practitioners to embrace these new ideas in bioassessment. Comprehensive and unbiased coverage of the previous literature was accomplished by querying online search engines, primarily Google Scholar, with search terms as they relate to open science (e.g., "reproducibility", "data science", "open source") and with Boolean operators to find applications to bioassessment (e.g., "reproducibility AND bioassessment"). Studies were included if they provided general overview of open science concepts that were relevant to bioassessment or if they directly described open science applications to bioassessment, although the latter were scarce. Emphasis was given to the breadth of research that has supported the development of open source software applications that can aid bioassessment, both as general tools and more specific programs tailored for indicator development. We excluded studies that described applications with citizen science components. Although citizen science can be a valuable tool for researchers and managers, methods for effective implementation are beyond the scope of this review.

Our objectives are to 1) provide a general overview of principles of open science and 2) empower the research community by providing examples of how these principles can be applied to bioassessment. For the second objective, we also provide a case study of stream bioassessment in the urban landscape of southern California to demonstrate a successful proof of concept. Herein, open science 'tools' describe best practices and specific applications that use an open philosophy to support applied science. We structure the review by first introducing open science principles, then describing how these principles could be applied to bioassessment (i.e., developing goals, curating data, and applying open-source software) including a case study 
120 example, and lastly providing a discussion of limitations and opportunities to better contextualize 121 real world applications of open science.

\section{Principles of open science}

123 Conventional modes of creating scientific products and more contemporary approaches that align with open science principles share the same goals. Both are motivated by principles of the scientific method that make the process of discovery transparent and repeatable. Where the conventional and open science approaches diverge is the extent to which technological advances facilitate the entire research process. Distinction between the two approaches can be conceptualized as the "research paper as the only and final product" for the conventional approach, whereas the open science approach is inherently linked to advances in communication and analysis that have been facilitated by the Internet and computer sciences (Table 1). As a result, the open science approach can enhance all aspects of the scientific process from initial conception of a research idea to the delivery and longevity of a research product (Figure 1). The process is iterative where products are improved by the individual and/or others, facilitated by open science tools that enhance access and reproducibility of data.

135 The paradigm of the research paper as a final scientific product can inhibit the uptake of research methods and findings by environmental managers. The research paper is conventionally viewed as a communication tool for scientists to report and share results among peers. Researchers access periodicals to stay informed of scientific advances and use the information to replicate and improve on methods for follow-up analysis. Although the primary literature continues to serve this critical role, this workflow is problematic when scientific products are needed to serve interests outside of the research community. For example, the paper as an endpoint for environmental managers fails to deliver products that are easily accessible from the practitioner's perspective, both in application and interpretation. A research paper is less likely to effect environmental change because it does not provide a mechanism to transfer actionable information to those that require scientific guidance for decision-making, such as sharing analysis code or results that describe output from assessment products. Numerous studies have documented implementation failures as a result of siloing among research communities where the flow of information does not extend beyond institutional walls (e.g., Mitchell 2005, Liu et al. 2008). Information loss over time is another concern associated with the paradigm of research paper as final product (Michener et al. 1997), particularly as intimate knowledge of study details is lost as new projects are initiated or individuals leave institutions.

\section{Open data as a component of the open science process}

Open data is a fundamental component of the broader open science process described in Figure 1. Under this mode of thinking, the research team becomes stewards of its data. For bioassessment data, government institutions may be the primary stewards of information that supports product development within a broader research team. Stewardship allows the data to be treated as a dynamic product with a traceable and replicable provenance (i.e., origin), rather than proprietary and serving only the internal needs of an immediate research goal. Metadata that describe the structure and history of a dataset ensure the data have an identity. Metadata also encourage adoption of core data structures that allow integration across different sources, which is critical for collaboration across institutional boundaries (Horsburgh et al. 2016, Hsu et al. 
162 2017). Other open science practices, such as integration of data with dynamic reporting tools or

163 submitting data to a federated repository (i.e., a decentralized database system for coordination

164 and sharing), can facilitate communication for researchers and those for which the research was

165 developed (Bond-Lamberty et al. 2016). Prominent examples that can benefit next-generation

166 bioassessment methods, such as molecular-based techniques for species identification, include

167 the BarCode of Life Data Systems (BOLD) and GenBank repositories.

168 Open data can benefit research by contributing to an increase in novel products created through

169 collaboration. Collaborative publications have increased in the environmental sciences as

170 research teams leverage open data to create synthesis products that allow novel insights from

171 comparisons across multiple datasets. Quantitative meta-analyses and systematic reviews are

172 increasingly used to extract information from the primary literature (Carpenter et al. 2009, Lortie

173 2014). In addition, open data products can increase efficiency of the individual researcher and a

174 collective research team by encouraging collaborators to adopt an open science workflow. Many

175 tools developed within the software and computer science community to facilitate open process

176 and the creation of open data are now easily accessible to environmental scientists (Yenni et al.

177 2019). Version control software (e.g., Git, GitHub), open source programming languages (e.g.,

178 R, Python), and integrated development environments (IDEs, e.g., RStudio, Spyder) can all be

179 leveraged to dynamically create and share open data products that can build institutional

180 memory. These tools promote deliberate and shared workflows among researchers that can lead

181 to better science in less time (Lowndes et al. 2017) and have proven useful in recent applications

182 in the hydrologic sciences (Idaszak et al. 2017, Slater et al. 2019).

183 Open access to data can also benefit management and regulatory communities. Openness can

184 improve the value of data from monitoring programs by facilitating data discovery and synthesis,

185 often through the adoption of a common metadata structure and integration of data within

186 federated data networks (e.g., DataONE, iRODS). Research institutions can also use open data

187 maintained by management or regulatory communities to develop products that directly support

188 the mission of the latter, e.g., assessment methods developed from long-term monitoring datasets

189 that identify priority areas to focus management actions or fulfill regulatory obligations. Open

190 data can also improve public trust in scientific findings by exposing the underlying information

191 used to develop a research product (Grand et al. 2012). Similar concepts are used in

192 "blockchain" technologies that allow public financial transactions in an open, distributed format,

193 as for trading in cryptocurrencies (Pilkington 2016). Increased trust could facilitate eventual

194 adoption of proposed rules or regulations that are based on research products created from open

195 data. More efficient and effective implementation of potential regulations may also be possible if

196 supporting data are openly available.

\section{Applying open science principles to bioassessment}

198 Here we provide a detailed description of open science processes that the bioassessment

199 community could leverage to create reproducible, transparent, and discoverable research

200 products for environmental managers. The below examples require understanding the distinction

201 between the general open science process in Figure 1, open data as an individual component of

202 the open science process, and the technology-based tools that can be used to achieve these ends.

203 Both the tools and open data are critical components that facilitate the broader process to achieve

204 the principles outlined in Table 1. "Openness" of process, tools, and data exists on a continuum,

Peer] reviewing PDF | (2020:03:46407:2:0:NEW 18 Jun 2020) 
205

206

207

208

209

210

211

212

213

214

215

216

217

218

219

220

221

222

223

224

225

226

227

228

229

230

231

232

233

234

235

236

237

238

239

240

241

242

243

244

245

246

247

248

and incremental improvements can transform an individual's and research group's practice over time. We encourage awareness that an open process adopts the open science tools that are appropriate for a research question and the creation of open data can be a fundamental component of the process. Acceptance by the research team and collaborators of the concepts described in Table 1 is critical to achieving openness.

The overall process is shown in Figure 2 as an expansion of general concepts in Figure 1. This iterative flow of information is facilitated by 1) openly sharing planning documents, 2) using established metadata standards to document synthesized data products, 3) hosting data products on open repositories, 4) creating reproducible summary documents that integrate the data and research products, and 5) incorporating the developed product into interactive applications that deliver the results to the managers and stakeholders. The technical phase of defining research goals, collecting and synthesizing data, and developing the bioassessment product are primary tasks of the research team. However, the open science process is distinguished by the flow of information to and from the research phase that can benefit the specific project and the science of bioassessment as a whole.

\section{Developing bioassessment goals}

In an open science process, the goals identified by the research team for developing a bioassessment product should occur through direct, two-way interaction with the management or regulatory institution that requires the product. Although such an approach has historically been used to develop bioassessment products, the interaction in an open science workflow differs in how information is exchanged. This exchange can be accomplished through direct communication and sharing of planning documents to ensure all decisions are transparent, i.e., open planning. In person meetings are ideal, but planning documents are dynamic and will require remote sharing and revision as ideas progress. Online tools such as Google documents, Slack discussion channels, and open lab notebooks can be instrumental for collaboration. More informal approaches, such as blogging and sharing ideas on social media, can expose new concepts to the broader community for guidance (Woelfle et al. 2011, Darling et al. 2013). Overall, the research team should use these tools to identify stakeholder needs while also considering the balance between the research goals and limitations of the data to meet these goals. This approach will ensure that the needs of the management and stakeholder communities will be consistent with the services provided by the research product.

An important practice that is not often used in bioassessment for project planning is study preregistration. This is a relatively new addition to the philosophy of open science that allows a research team to define their study procedures, expected outcomes, and statistical analysis plans in advance of the actual study (Munafó et al. 2017). Although the standard scientific method may seem to support such proactive practices, pre-registration is an explicit declaration to make the intentions of a study design clear to avoid publication bias where only positive outcomes are reported and to prevent an interpretive result where the researcher retrospectively defines study objectives after initial results are obtained if they do not agree with expectations. This latter issue is a serious concern where scientists use postdiction with significant hindsight bias in place of prediction and conventional hypothesis testing to inform scientific discovery (Nosek et al. 2018). Registered reports can also be used as a publishing format where an initial study design is peerreviewed and the article is provisionally accepted by a journal if the results are created with methods that do not deviate from the accepted design. This promotes greater coverage in the 
249 primary literature of null conclusions that otherwise may not have been published, reducing bias 250 for publishing positive results.

251 Pre-registration has been used extensively in clinical research (Dickersin and Rennie 2003),

252 where outcomes often have immediate implications for human health and well-being. In contrast,

253 bioassessment studies often focus on developing applied products, where conventional

254 hypothesis testing is less a concern. Studies are typically methods-focused where a research

255

256

257

258

259

260 product is developed to address a management or regulatory need, rather than a specific research question with a testable hypothesis. However, pre-registration could be an important tool for the environmental sciences where an explicit declaration of study intent as being applied or methods-focused could prevent postdiction or an otherwise misuse of study results after a project is completed. Existing venues that support pre-registration of studies across multiple disciplines could be used in bioassessment study planning (e.g., Open Science Framework, AsPredicted).

\section{Curating bioassessment data}

263

264

265

266

267

268

269

270

271

272

273

274

275

276

277

278

279

280

281

282

283

284

285

286

287

288

289

290

291

After project goals are established, the research team identifies requirements and sources of data that need to be synthesized to meet the research needs. Bioassessment data, or more generally, biological data obtained from field sampling have a unique set of challenges that require added vigilance in data stewardship (Cao and Hawkins 2011). Species identification requires a tradeoff between taxonomic specificity and cost (Lenat and Resh 2001, Chessman et al. 2007). Species names also change regularly requiring updates to standard taxonomic effort (STE) tables that are critical for many biological indices, although some standardized databases have facilitated broadscale comparisons (e.g., World Register of Marine Species, Costello et al. 2013). Unidentified or ambiguous taxa must also be explicitly treated in analysis workflows (Cuffney et al. 2007), e.g., are they treated as missing values or are they substituted with coarser taxonomic designations? In contrast, molecular techniques based on DNA barcoding eliminate the need for direct species collection and morphological identification (Deiner et al. 2017, Hering et al. 2018). These nextgeneration approaches have capitalized on advances in database development that allow open access by diverse researchers across disciplines and are well-suited for the development of additional open science tools. Despite these advances, molecular-based approaches have also suffered from challenges related to standardization of workflows and coverage of reference databases (White et al. 2014, Elbrecht et al. 2017).

Open science tools can facilitate the curation of bioassessment data by addressing the above challenges. For example, a multimetric index may require taxonomic data collected at multiple sites by different institutions, whereas the output data may include summary scores, individual metrics, and any additional supporting information to assess the quality of the output. In an open science workflow, these data products can be documented using a standardized metadata language (e.g., Ecological Metadata Language Standard, or EML) which describes the who, what, and why to ensure the data have an identity. Adoption of a metadata standard also ensures that a machine-readable file is produced to allow integration into a data repository. This will allow a synthesized data product to be discoverable beyond the specific research application and will provide metadata to help others understand the context of the data (e.g., Idaszak et al. 2017). Finally, the dataset can be assigned a unique digital object identifier (DOI, e.g., through Zenodo) that provides a permanent address and is also citable to allow researchers to track usage of a bioassessment data product. 
292 In an open paradigm, the data itself is a product to achieve the research goals and also becomes

293 available to the research and management community as a fully documented source of

294 information that has value beyond the specific project. The openness of the synthesized data

295 product is one of the primary means of facilitating the application of a bioassessment product.

296 The synthesized data product can be used by the research team to create interactive applications

297 for stakeholders to share and explore the data and is also fully integrated into summary reports

298 using software for generating dynamic documents (e.g., using knitr, Xie 2015, RMarkdown,

299 Allaire et al. 2018, Jupyter notebooks, Kluyver et al. 2016). Continuous integration services can

300 automate quality control and regularly update data products as new information is collected

301 (Yenni et al. 2019). The data product also becomes available on an open data repository that is

302 discoverable by other researchers and can contribute to alternative scientific advances beyond the

303 immediate goals (e.g., Hydroshare for the hydrologic sciences, Idaszak et al. 2017).

\section{Using R for bioassessment application}

305 The R statistical programming language (RDCT 2018) is one of the most commonly used analysis platforms in the environmental sciences (Lai et al. 2019, Slater et al. 2019) and many

307 existing $\mathrm{R}$ packages have value for the bioassessment community (Table 2). For managing the

308 day to day tasks of working with multiple datasets, the tidyverse suite of packages provides the

309

310 necessary tools to import, wrangle, explore, and plot almost any data type (Wickham 2017). The tidyverse also includes the powerful ggplot2 package that is based on a syntactical grammar of graphics for plotting (Wilkinson 2005, Wickham 2009). This package provides a set of independent plotting instructions that can be built piecewise and is a departure from other graphics packages that represent a collection of special cases that limit the freedom of the analyst. In bioassessment, ggplot 2 can be used both in an exploratory role during the development phase and also to create publication quality graphics.

316 Bioassessment data are inherently spatial and recent package development has greatly improved

317 the ability to analyze and map geospatial data in $\mathrm{R}$. The raster package can used to read/write,

318 manipulate, analyze, and model grid-based spatial data (Hijmans 2019), which are often common

319 supporting layers for bioassessment (e.g., elevation or climate data). For vector data (i.e., points, 320 lines, and polygons), the sf package ("simple features", Pebesma 2018) uses principles of data 321 storage that parallel those from the tidyverse by representing spatial objects in a tidy and tabular format. This facilitates analysis by presenting complex spatial structures in a readable format that can be integrated in workflows with existing packages, including other mapping packages (e.g., leaflet, Cheng et al. 2018, or mapview, Appelhans et al. 2018). This allows the research team to use a workflow that is focused in a single environment, rather than using separate software for statistical and geospatial analysis.

$\mathrm{R}$ is fundamentally a statistical language and several existing $\mathrm{R}$ packages can be used to evaluate and support bioassessment data. Random forest models have been used to develop predictive bioassessment indices that compare observed taxa to modeled expectations (i.e., O/E indices). The randomForest package (Liaw and Wiener 2002) uses an ensemble learning approach that is robust to complex, non-linear relationships and interactions between variables. These models are particularly useful with large, regional datasets that describe natural and anthropogenic gradients in condition (Laan and Hawkins 2014, Mazor et al. 2016). The nlme package can be used to create non-linear mixed effect models that are more flexible than standard regression approaches (Pinheiro et al. 2018). The nlme package can develop models for nested sampling designs, such 
336

337

338

339

340

341

342

343

344

345

346

347

348

349

350

351

352

353

354

355

356

357

358

359

360

361

362

363

364

365

366

367

368

369

370

371

372

373

374

375

376

377

378

379

as repeat visits to sample sites or otherwise confounding variables that contribute information but are not unique observations (Mazor et al. 2014). The mgcv package provides similar functionality as nlme, but uses an additive modeling approach where individual effects can be evaluated as the sum of smoothed terms (Wood 2017). The mgcv package is often applied to model biological response to stressor gradients (Yuan 2004, Taylor et al. 2014).

Other R packages have been developed specifically for bioassessment. For example, the TITAN2 package can be used to develop quantitative evidence of taxon-specific changes in abundance and occurrence across environmental gradients (Baker et al. 2015). Results from this package can support exploratory analysis for developing bioassessment products, such as identifying indicator species or establishing numeric criteria (Taylor et al. 2018). The results can be also be used post hoc to evaluate potential response of a biological index with changing environmental conditions, such as proposed management actions for rehabilitation (King et al. 2011). Alternatively, the indicspecies package provides similar functionality but is based only on species occurrence or abundance matrices across sites (De Caceres and Legendre 2009). This package can be used to identify species at sites if continuous environmental data are unavailable, such as those that are representative of reference conditions (Bried et al. 2014). Finally, the vegan package has been a staple among community ecologists for multivariate analyses in $\mathrm{R}$ (Oksanen et al. 2018).

Although the R network includes over 15000 user contributed packages, only a handful of these packages are specific to bioassessment. Community practices have allowed $\mathrm{R}$ to reach new audiences where new packages build on the work of others and are transportable between users and operating systems. Formalized communities, such as rOpenSci, encourage standardization and review of contributed packages within the ecological sciences to make scientific data retrieval reproducible. Several tools have also been developed and published in the last five years that greatly simplify the process of creating new packages in R (Wickham 2015, Wickham et al. 2018). The advantages of creating and sharing $R$ packages that are specific to bioassessment applications are important for several reasons. First, an R package compartmentalizes technical instructions developed during the research phase that can be executed by anyone with access to the software. R packages also require explicit documentation of the functions and data requirements. As such, package users will not only have access to underlying code but also understand the why and what for different package functions.

Finally, R can be used to create interactive applications that deliver bioassessment products to stakeholders and managers in entirely novel contexts. In particular, the shiny package provides programming tools built around concepts of reactivity, where data inputs and outputs can be modified in real time (Chang et al. 2018). A shiny application is an interactive user interface that is developed with $\mathrm{R}$ code, but is a standalone product that can be used without any programming experience. These applications are deployed online and can extend the reach of bioassessment products to those that require the information for decision-making but otherwise do not have the time or resources to learn R. Applications built in shiny can also be easily linked to other R packages. For example, a shiny website could be created to allow users to upload raw data and estimate and report bioassessment scores using an R package developed externally. Moreover, shiny applications are completely customizable and can be tailored by the developer to the specific needs of any user. This distinction separates shiny from other web-based analysis platforms. 


\section{Open science in practice: The SCAPE project}

381 Although bioassessment products have been sufficiently developed in California (USA), there

382 are no narrative or numeric criteria in place to support designated aquatic life uses in wadeable

383 streams, nor are bioassessment data actively used to support conservation or watershed

384 management. Indices using benthic macroinvertebrates and algae have been developed that

385

386

387

388

389

390

391

392

393 provide consistent indications of biological condition across the diverse geography and climates in the state (Fetscher et al. 2013, Mazor et al. 2016, Ode et al. 2016). A physical habitat index has also been developed that provides complementary information supporting bioassessment data (Rehn et al. 2018). Combined, these indices represent significant achievements in overcoming technical challenges for developing accurate and interpretable bioassessment products. However, these products are not used at a statewide scale to inform decisions and past efforts for stream management have only used a fraction of available products. A synthesis of condition assessments is needed to effectively implement bioassessment products in California and data must be presented in a context that is relevant to the needs of decision makers.

394 Recent regulatory initiatives in California have established a foundation for openness that could

395

396

397

398

399

400

401

402

403

404

405

406

407

408

409

410 greatly improve the application of bioassessment products to support decision-making. In particular, these initiatives have set a precedent for openly sharing data collected with public funds. The Open and Transparent Water Data Act passed by the state legislature in 2016 requires water quality institutions to "create, operate, and maintain a statewide integrated water data platform that, among other things, would integrate existing water and ecological data information from multiple databases and provide data on completed water transfers and exchanges" (AB 1755, Dodd, 2015-2016). This legislation also calls for state agencies to "develop protocols for data sharing, documentation, quality control, public access, and promotion of open-source platforms and decision support tools related to water data". These aspirations were further supported by a resolution on July 10, 2018 that formally committed the State Water Resources Control Board to "provide broader access to data used to make local, regional, and statewide water management and regulatory decisions in California". These recent initiatives in California have similarly been observed at the national level. For example, the Data Coalition is an advocacy group that operates on behalf of the private and public sector for the publication of government data in a standardized and open format. The Internet of Water also operates at the national-level by focusing on strengthening connections between data producers and users through centralized data hubs and data standards.

412 Open science tools have recently been used in California to address bioassessment

413 implementation challenges in developed landscapes. The Stream Classification and Priority

414 Explorer, or SCAPE (Beck 2018a, Beck et al. 2019), was developed using an open science

415 framework to help identify reasonable management goals for wadeable streams using existing

416 bioassessment and watershed data. The SCAPE tool represents both a modeling approach to help

417 prioritize management goals (Figure 3) and a set of open science products for direct application

418 to environmental managers. The modeling component addresses a practical problem of achieving

419 reference conditions in developed landscapes, where channel modification is common. Using the

420 National Hydrography Dataset (NHD-Plus; McKay et al. 2012) and watershed predictors

421 (StreamCat; Hill et al. 2016), the model classifies stream segments as biologically "constrained"

422

423 or "unconstrained" by landscape alteration. This classification system can be used to set management priorities based on the constraint class. For example, a monitoring site with an 
424 observed biological index score that is above a predicted range could be assigned a higher

425 management priority relative to a site that is scoring within the range that is expected based on

426 landscape development.

427 Open science tools were critically important for translating and delivering SCAPE products to 428 decision-makers. Local stakeholder engagement to identify research goals guided the technical 429 development process of SCAPE. All analyses, including model development and validation, 430 were conducted using R. A version control system (Git) and online hosting (GitHub) also 431 allowed full transparency of decisions that were made to create the SCAPE model. A permanent 432 DOI was assigned through Zenodo to track downloads and portability of source code (Beck 433 2018a). Importantly, an online, interactive web page (https://sccwrp.shinyapps.io/SCAPE) 434 greatly increased the impact and relevance of SCAPE by improving stakeholder understanding 435 through direct interaction with key decision points that influenced model output. A manuscript describing the technical components of the model was created using knitr and RMarkdown (Xie 2015, Allaire et al. 2018). This increased efficiency of the writing process also minimized the potential of introducing errors into tables or figures by eliminating the need to copy results between different writing platforms. Finally, a geospatial data file from the model was also made public on a federated data repository, which included metadata and plain language documentation to track provenance of the original information (Beck 2018b).

\section{Limitations and opportunities}

443 Although the case for open science in bioassessment is appealing, the widespread adoption of these principles in practice is inhibited by inertia of existing practices, disciplinary culture, and institutional barriers. Conventional and closed workflows used by many scientists are adopted and entrenched because of ease of use, precedence, and familiarity, yet they can be inefficient, inflexible, and difficult to communicate or replicate. Open science tools can improve analysis, documentation, and implementation through greater flexibility, but they expose research teams to entirely new concepts and skillsets in which they may never have been trained (e.g., Idaszak et al. 2017). Not only are the required skillsets demanding, but the open science toolbox continues to expand as new methods are developed and old methods become obsolete. This requires a research team to stay abreast of new technologies as they are developed and weigh the tradeoffs of adopting different workflows for different research tasks.

Advocates for open science are well aware of the technical challenges faced by individuals and research teams that have never been exposed to the core concepts. Most importantly, education and training (e.g., through The Carpentries) remain key components for developing skillsets among researchers where the focus is both on learning new skills for transferability and realizing their value for improving science as a whole (Hampton et al. 2017). A goal of many training curricula is to instill confidence in new users by developing comfort with new workflows, such as replacing a point-and-click style of analysis with one focused on using a command line through a computer terminal. Other approaches to demonstrate the value of new techniques use a side by side approach of closed vs open workflows to show the increased efficiency and power of the latter. Adoption becomes much more reasonable once users realize the value of investing in learning a new skill. 
465 Advocates of open science also recognize the limitations of teaching in that not all audiences can

466 be reached and not all materials are retained or even used after training. A strategy of

467 empowering trainees to become trainers and teach others at their home institutions (e.g., train-

468 the-trainer workshops and programs) enables open science to reach more individuals, and

469 benefits science more broadly as they develop technical and communication skills, and build

470

471 local communities. Those that also adopt new workflows through training can also direct their research products to facilitate collaboration with non-adopters rather than the latter synthesizing

472

473

474

475

476

477

478

479

480

481

482 and analyzing their data in potentially suboptimal ways (Touchon and McCoy 2016). These "champions" can be a voice of encouragement for others by demonstrating how new tools can be introduced and learned over time through shared experiences (Lowndes et al. 2017). This also encourages the development of a community of practice that shares and learns together to navigate the collection of existing and developing open science tools (Stevens et al. 2018). Champions of open science should also be vocal proponents that spread awareness of the value of open science tools, particularly to those that make decisions on project resources. Department heads or administrative leaders may not be aware of the value of investing in open science, particularly if the consequences of not doing so are externalized in indirect costs that are not budgeted. A change in mindset may be needed where open science is viewed as a core tool that is critical to maintaining relevance of a research program in the future (Hampton et al. 2017).

483 Many scientists feel they cannot prioritize learning new skills given existing demands on their 484 time, particularly if the benefits of these approaches, such as the value for the research team of sharing their data, are not apparent or immediate. Short-term funding and even political cycles can disincentivize scientists from spending time on anything but contractually obligated deliverables, which as noted above, may not effectively apply science in decision-making. This is an acute concern for early career scientists that have higher demands on establishing reputation and credentials, where investments in open science may be seen as detracting from progress (Allen and Mehler 2019). As an alternative, a practical solution is to actively encourage the investment in open science within the research team or lab, as opposed to placing the burden on the individual as an isolated researcher (i.e., team science, Cheruvelil and Soranno 2018). Laboratory or department heads should allow and encourage research staff to invest time in learning new skills and exploring new ideas, even if this does not immediately benefit the latest project. Over time, small investments in developing new skills will have long-term payoffs, particularly if a growing skillset among the research team encourages networking and peer instruction (Lowndes et al. 2017, Allen and Mehler 2019). Developing an environment where open science tools are highly valued and encouraged may also increase job satisfaction and benefit recruitment and retention if researchers are allowed the space and time to develop skills beyond the current project.

The scientific culture within a discipline or institution may inhibit the adoption of open science methods. A common argument against open science is the protection of data that an individual research team may view as proprietary or sensitive. There are reasonable arguments to treat data as personal property, particularly if exceptional effort was spent to secure funding for a project and if the data were hard-earned or sensitive, e.g., detailed location data on endangered species or medical/socioeconomic data (Zipper et al. 2019). These issues are less of a concern for bioassessment where many datasets are collected by institutions that are publicly funded and data accessibility may be mandated by law. However, an open science process dictates that both interim and completed research products derived from public data should be available to the 
510 broader bioassessment community. This raises an additional concern that research teams using

511 transparent workflows could expose themselves to increased criticism by their peers and the

512 public (Lewandowsky and Bishop 2016, Allen and Mehler 2019), particularly where the

513 developed products can have important regulatory implications.

514 Feedback and criticism are fundamental and natural parts of the scientific process. Scientists

515 receive feedback at many stages in the conventional scientific workflow (e.g., internal review,

516 peer-review, presentations at conferences). Potentially new and challenging avenues for feedback

517 are created in an open workflow. A concern is that openness can provide a platform for

518 antagonistic or even hostile views, which could alter or degrade the scientific product (Landman

519 and Glantz 2009, Lewandowsky and Bishop 2016). However, opportunities for addressing

520 alternative viewpoints are critical to the open process of creating applied products, even if some

521 voices are politically charged. This is especially true in bioassessment where finished products

522 that could be adopted in regulation are often heavily scrutinized. It is in the interest of applied

523 scientists to hear the concerns of all parties during the development phase. This is not to provide

524 an avenue to erode the integrity or objectives of the science, but to enable full knowledge of the

525 very real barriers to adoption that exist when science is applied in regulation. Openness that

526 invites all voices to participate is a much more agreeable path to consensus than producing the

527 science in isolation of those that it affects (Pohjola and Tuomisto 2011). Ultimately, these

528 products are developed to improve the environment as a public resource and the ideals promoted

529 by an open science process directly align with these goals.

530 Institutional barriers can inhibit open science given the scale of change that must occur for 531 adoption. Bureaucratic hurdles can disincentivize initiatives that promote change, particularly if 532 that change originates from researchers not in administrative roles. Regulatory institutions may 533 also prefer some level of opacity for how research products that influence policy are made

534 available during development. The level of transparency advocated by open science could be

535 viewed as opening the floodgates to increased legal scrutiny that can unintentionally hinder

536 forward progress. Despite these reservations, many public institutions now advocate for

537 increased openness because of the benefits that facilitate and engender public trust. Open data

538 initiatives are now fairly common and represent a form of advocacy by public institutions for

539 broader adoption of open science principles. Many national-level data products already exist that

540 embrace openness to invest in the quality and availability of data (e.g., National Water Quality

541 Monitoring Council initiatives, US Geological Survey products through NWIS and BioData, US

542 Environmental Protection Agency through STORET/WQX). Internationally, institutions in

543 Europe and Canada that have projects supported by public funds are obligated to publish data

544 and papers as open access (Horizon 2020, Tri-Agency Open Access Policy). Although past

545 efforts and recent changes represent progress, many institutions have yet to strictly define open

546 science and how it is applied internally and externally. As open science continues to build

547 recognition, means of integrating toolsets that promote openness and transparency beyond

548 publicly shared data will have to be adopted by regulatory and management institutions.

\section{Conclusions}

550 The relevance of bioassessment applications can be improved with open science by using

551 reproducible, transparent, and effective tools that bridge the gap between research and

552 management. Many open science tools can improve communication between researchers and

Peer] reviewing PDF | (2020:03:46407:2:0:NEW 18 Jun 2020) 
553

554

555

556

557

558

559

560

561

562

563

564

565

566

567

568

569

570

571

572

573

574

575

576

577

578

582

583

584

585

586

587

588

589

managers to expose all aspects of the research process and facilitate implementation to support policy, regulation, or monitoring efforts. Communication ensures that the developed product is created through an exchange of ideas to balance the potentially competing needs of different sectors and institutions. The documentation and archiving of data used to create a bioassessment product also ensures that other researchers can discover and build on past efforts, rather than constantly rebuilding the wheel. Incremental improvements of existing products can reduce the proliferation of site- and taxon-specific methods with limited regional applications by exploring new ways to integrate biological indicators across space and time.

Efforts to formally recognize and integrate open science in bioassessment are needed now more than ever. The transition of bioassessment from taxonomic-based indices to molecular approaches presents novel challenges that will only increase in severity as researchers continue to refine methods for molecular applications (Baird and Hajibabaei 2012). Although molecularbased indices share similar assessment objectives as conventional indices, the data requirements and taxonomic resolution are substantially more complex. Bioassessment researchers developing molecular methods are and will continue to be inundated with data from high-throughput DNA sequencers. Systematic approaches to document, catalog, and share this information will be required to advance and standardize the science. Molecular approaches are also dependent on existing reference libraries for matching DNA samples for taxonomic identification. The integrity of reference libraries depends greatly on the quality of metadata and documentation for contributed samples. Open science principles should be leveraged in this emerging arena to ensure that new bioassessment methods continue to have relevance for determining the condition of aquatic resources.

\section{Acknowledgments}

The authors acknowledge support from the San Gabriel River Regional Monitoring Program and the Sanitation Districts of Los Angeles County. We thank Eric Stein for reviewing an earlier draft of the manuscript. We thank Mike McManus for assistance with the conceptual diagrams.

\section{References}

Allaire, J., Y. Xie, J. McPherson, J. Luraschi, K. Ushey, A. Atkins, H. Wickham, J. Cheng, and W. Chang. 2018. Rmarkdown: Dynamic documents for R. https://CRAN.Rproject.org/package $=$ rmarkdown .

Allen, C., and D. M. A. Mehler. 2019. Open science challenges, benefits and tips in early career and beyond. PLoS Biology 17:e3000246.

Appelhans, T., F. Detsch, C. Reudenbach, and S. Woellauer. 2018. Mapview: Interactive viewing of spatial data in R. https://github.com/r-spatial/mapview.

Baird, D. J., and M. Hajibabaei. 2012. Biomonitoring 2.0: A new paradigm in ecosystem assessment made possible by next-generation dna sequencing. Molecular Ecology 21:20392044. 
590 Baker, M. E., R. S. King, and D. Kahle. 2015. TITAN2: Threshold indicator taxa analysis.

591 https://CRAN.R-project.org/package=TITAN2.

592 Beck, M. W. 2018a. SCCWRP/SCAPE: v1.0 (Version 1.0). Zenodo,

593 http://doi.org/10.5281/zenodo.1218121.

594 Beck, M. W. 2018b. Constrained streams for biological integrity in California. Knowledge

595 Network for Biocomplexity. urn:uuid:75411f50-32ed-42a5-bbfd-26833c7a441f.

596 Beck, M. W., and L. K. Hatch. 2009. A review of research on the development of lake indices of 597 biotic integrity. Environmental Reviews 17:21-44.

598 Beck, M. W., R. D. Mazor, S. Johnson, K. Wisenbaker, J. Westfall, P. R. Ode, R. Hill, C. Loflen, 599 M. Sutula, and E. D. Stein. 2019. Prioritizing management goals for stream biological integrity 600 within the developed landscape context. Freshwater Science 38:883-898.

601 Birk, S., W. Bonne, A. Borja, S. Brucet, A. Courrat, S. Poikane, A. Solimini, W. van de Bund, N. 602 Zampoukas, and D. Hering. 2012. Three hundred ways to assess Europe's surface waters: An 603 almost complete overview of biological methods to implement the Water Framework Directive. 604 Ecological Indicators 18:31-41.

605 Bond-Lamberty, B., A. P. Smith, and V. Bailey. 2016. Running an open experiment:

606 Transparency and reproducibility in soil and ecosystem science. Environmental Research Letters $607 \quad 11: 1-7$.

608 Borja, A., S. B. Bricker, D. M. Dauer, N. T. Demetriades, J. G. Ferreira, A. T. Forbes, P.

609 Hutchings, X. Jia, R. Kenchington, J. C. Marques, and C. Zhu. 2008. Overview of integrative

610 tools and methods in assessing ecological integrity in estuarine and coastal systems worldwide.

611 Marine Pollution Bulletin 56:1519-1537.

612 Borja, A., M. Elliot, J. H. Anderson, T. Berg, J. Carstensen, B. S. Halpern, A. S. Heiskanen, S.

613 Korpinen, J. S. S. Lowndes, G. Martin, and N. Rodriguez-Ezpeleta. (2016). Overview of

614 integrative assessment of marine systems: The ecosystem approach in practice. Frontiers in

615 Marine Science 3:20.

616 Borja, A., J. M. Garmendia, I. Menchaca, A. Uriarte, and Y. Sagarmínaga. 2019. Yes, we can!

617 Large-scale integrative assessment of european regional seas, using open access databases.

618 Frontiers in Marine Science 6.

619 Borja, A., A. Ranasinghe, and S. B. Weisberg. 2009. Assessing ecological integrity in marine

620 waters, using multiple indices and ecosystem components: Challenges for the future. Marine

621 Pollution Bulletin 59:1-4.

622 Bried, J. T., S. K. Jog, A. R. Dzialowski, and C. A. Davis. 2014. Potential vegetation criteria for 623 identifying reference-quality wetlands in the south-central United States. Wetlands 34:11596241169.

625 Cao, Y., and C. Hawkins. 2011. The comparability of bioassessments: A review of conceptual 626 and methodological issues. Journal of the North American Benthological Society 30:680-701. 
627 Carpenter, S. R., E. V. Armbrust, P. W. Arzberger, F. S. C. III, J. J. Elser, E. J. Hackett, A. R.

628 Ives, P. M. Kareiva, M. A. Leibold, P. Lundberg, M. Mangel, N. Merchant, W. W. Murdoch, M. 629 A. Palmer, D. P. C. Peters, S. T. A. Pickett, K. K. Smith, D. H. Wall, and A. S. Zimmerman.

630 2009. Accelerate synthesis in ecology and environmental sciences. BioScience 59:699-701.

631 Chang, W., J. Cheng, J. Allaire, Y. Xie, and J. McPherson. 2018. Shiny: Web application

632 framework for R. https://CRAN.R-project.org/package=shiny.

633

634 Cheng, J., B. Karambelkar, and Y. Xie. 2018. Leaflet: Create interactive web maps with the 635 javascript 'leaflet' library. https://CRAN.R-project.org/package=leaflet.

636 Cheruvelil, K. S., and P. A. Soranno. 2018. Data-intensive ecological research is catalyzed by 637 open science and team science. BioScience 68:813-822.

638 Chessman, B., S. Williams, and C. Besley. 2007. Bioassessment of streams with 639 macroinvertebrates: Effect of sampled habitat and taxonomic resolution. Journal of the North 640 American Benthological Society 26:546-565.

641 Collins, S. L. 2016. Vegetation science in the age of big data. Journal of Vegetation Science $642 \quad 27: 865-867$.

643 Costello, M. J., P. Bouchet, G. Boxshall, K. Fauchald, D. Gordon, B. W. Hoeksema, G. C. B. 644 Poore, R. W. M. van Soest, S. Stöhr, T. C. Walter, B. Vanhoorne, W. Decock, and W. Appeltans. 645 2013. Global coordination and standardisation in marine biodiversity through the World Register 646 of Marine Species (WoRMS) and related databases. PLoS One 8:e51629.

647 Cuffney, T. F., M. D. Bilger, and A. M. Haigler. 2007. Ambiguous taxa: Effects on the 648 characterization and interpretation of invertebrate assemblages. Journal of the North American 649 Benthological Society 26:286-307.

650 Dale, V. H., and S. C. Beyeler. 2001. Challenges in the development and use of ecological 651 indicators. Ecological Indicators 1:3-10.

652 Darling, E. S., D. Shiffman, I. M. Côte, and J. A. Drew. 2013. The role of Twitter in the life 653 cycle of a scientific publication. Ideas in Ecology and Evolution 6:32-43.

654 Davies, S. P., and S. K. Jackson. 2006. The biological condition gradient: A descriptive model 655 for interpreting change in aquatic ecosystems. Ecological Applications 16:1251-1266.

656 De Caceres, M., and P. Legendre. 2009. Associations between species and groups of sites:

657 Indices and statistical inference. Ecology. http://sites.google.com/site/miqueldecaceres/.

658 Deiner, K., H. M. Bik, E. Mächler, M. Seymour, A. Lacoursiére-Roussel, F. Altermatt, S. Creer, 659 I. Bista, D. M. Lodge, N. de Vere, M. E. Pfrender, and L. Bernatchez. 2017. Environmental 660 DNA metabarcoding: Transforming how we survey animal and plant communities. Molecular 661 Ecology 26:5872-5895.

662 Dickersin, K., and D. Rennie. 2003. Registering clinical trials. 290 4:516-523. 
663 Elbrecht, V., E. E. Vamos, K. Meissner, J. Aroviita, and F. Leese. 2017. Assessing strengths and 664 weaknesses of dna metabarcoding-based macroinvertebrate identification for routine stream 665 monitoring. Methods in Ecology and Evolution 8:1265-1275.

666 Essl, F., F. Courchamp, S. Dullinger, J. M. Jeschke, and S. Schindler. 2020. Make open access 667 publishing fair and transparent! BioScience 70:201-204.

668 Fetscher, A. E., R. Stancheva, J. P. Kociolek, R. G. Sheath, E. D. Stein, R. D. Mazor, P. R. Ode, and L. B. Busse. 2013. Development and comparison of stream indices of biotic integrity using diatoms vs. Non-diatom algae vs. A combination. Journal of Applied Phycology 26:433-450.

671 Fore, L. S., and C. Grafe. 2002. Using diatoms to assess the biological condition of large rivers 672 in Idaho (U.S.A.). Freshwater Biology 47:2015-2037.

673 Franco, A., N. Malhotra, and G. Simonovits. 2014. Publication bias in the social sciences:

674 Unlocking the file drawer. Science 345:1502-1505.

675 Grand, A., C. Wilkinson, K. Bultitude, and A. F. T. Winfield. 2012. Open science: A new "trust 676 technology"? Science Communication 34:679-689.

677 Hampton, S. E., S. S. Anderson, S. C. Bagby, C. Gries, X. Han, E. M. Hart, M. B. Jones, W. C. 678 Lenhardt, A. MacDonald, W. K. Michener, J. Mudge, A. Pourmokhtarian, M. P. Schildhauer, K. 679 H. Woo, and N. Zimmerman. 2015. The tao of open science for ecology. Ecosphere 6:1-13.

680 Hampton, S. E., M. B. Jones, L. A. Wasser, M. P. Schildhauer, S. R. Supp, J. Brun, R. R. 681 Hernandez, C. Boettiger, S. L. Collins, L. J. Gross, D. S. Fernández, A. Budden, E. P. White, T. 682 K. Teal, S. G. Labou, and J. E. Aukema. 2017. Skills and knowledge for data-intensive 683 environmental research. Bioscience 67:546-557.

684 Hampton, S. E., C. A. Strasser, J. J. Tewksbury, W. K. Gram, A. E. Budden, A. L. Batcheller, C. 685 S. Duke, and J. H. Porter. 2016. Big data and the future of ecology. Frontiers in Ecology and the 686 Environment 11:156-162.

687 Hawkins, C. P., R. H. Norris, J. Gerritsen, R. M. Hughes, S. K. Jackson, R. K. Johnson, and R. J. 688 Stevenson. 2000a. Evaluation of the use of landscape classifications for the prediction of 689 freshwater biota: Synthesis and recommendations. Journal of the North American Benthological 690 Society 19:541-556.

691 Hawkins, C. P., R. H. Norris, J. N. Hogue, and J. W. Feminella. 2000b. Development and 692 evaluation of predictive models for measuring the biological integrity of streams. Ecological 693 Applications 10:1456-1477.

694 Hawkins, C. P., J. R. Olson, and R. A. Hill. 2010. The reference condition: Predicting 695 benchmarks for ecological and water-quality assessments. Journal of the North American 696 Benthological Society 29:312-343.

697 Hering, D., A. Borja, J. Carstensen, L. Carvalho, M. Elliott, C. K. Field, A. S. Heiskanen, R. K. 698 Johnson, J. Moe, D. Pont, A. L. Solheim, and W. de Bund. 2010. The European Water 699 Framework Directive at the age of 10: A critical review of the achievements with 700 recommendations for the future. Science of the Total Environment 408:4007-4019. 
701 Hering, D., A. Borja, J. I. Jones, D. Pont, P. Boets, A. Bouchez, K. Bruce, S. Drakare, B.

702 Hänfling, M. Kahlert, F. Leese, K. Meissner, P. Mergen, Y. Reyjol, P. Segurado, A. Vogler, and

703 M. Kelly. 2018. Implementation options for DNA-based identification into ecological status

704 assessment under the European Water Framework Directive. Water Research 138:192-205.

705 Hijmans, R. J. 2019. Raster: Geographic data analysis and modeling. https://CRAN.R-

706 project.org/package $=$ raster.

707 Hill, R. A., M. H. Weber, S. G. Leibowitz, A. R. Olsen, and D. J. Thornbrugh. 2016. The

708 Stream-Catchment (StreamCat) dataset: A database of watershed metrics for the conterminous

709 United States. Journal of the American Water Resources Association 52:120-128.

710 Horsburgh, J. S., M. M. Morsy, A. M. Castronova, J. L. Goodall, T. Gan, H. Yi, M. J. Stealey,

711 and D. G. Tarboton. 2016. Hydroshare: Sharing diverse environmental data types and models as

712 social objects with application to the hydrology domain. Journal of the American Water

713 Resources Association 52:873-889.

714 Hsu, L., E. Mayorga, J. S. Horsburgh, M. R. Carter, K. A. Lehnert, and s. L. Brantley. 2017.

715 Enhancing interoperability and capabilities of earth science data using the Observations Data

716 Model 2 (ODM2). Data Science Journal 16:1-16.

717 Idaszak, R., D. G. Tarboton, H. Yi, L. Chistopherson, M. J. Stealey, B. Miles, P. Dash, A.

718 Couch, C. Spealman, D. P. Ames, and J. S. Horsburgh. 2017. HydroShare - a case study of the

719 application of modern software engineering to a large distributed federally-funded scientific

720 software development project. Pages 217-233 in J. Carver, N. P. C. Hong, and G. K.

721 Thiruvathukal, editors. Chapter 10 in software engineering for science. Taylor \& Francis CRC

722 Press, Boca Raton, Florida, USA.

723 Ihle, M., I. S. Winney, A. Krystalli, and M. Croucher. 2017. Striving for transparent and credible

724 research: Practical guidelines for behavioral ecologists. Behavioral Ecology 28:348-354.

725 Karr, J. R., K. D. Fausch, P. L. Angermeier, P. R. Yant, and I. J. Schlosser. 1986. Assessing

726 biological integrity in running waters: A method and its rationale. Illinois Natural History

727 Survey, Champaign, Illinois.

728 Kelly, M. G., S. Birk, N. J. Willby, L. Denys, S.Drakare, M. Kahlert, S. M. Karjalainen, A.

729 Marchetto, J. A. Pitt, G. Urbanič, and S. Poikane. 2016. Redundancy in the ecological

730 assessment of lakes: Are phytoplankton, macrophytes and phytobenthos all necessary? Science

731 of the Total Environment 15:594-602.

732 Kerans, B. L., and J. R. Karr. 1994. A benthic index of biotic integrity (B-IBI) for rivers of the

733 Tennessee Valley. Ecological Applications 4:768-785.

734 King, R. S., M. E. Baker, P. F. Kazyak, and D. E. Weller. 2011. How novel is too novel? Stream 735 community thresholds at exceptionally low levels of catchment urbanization. Ecological

736 Applications 21:1659-1678. 
737 Kluyver, T., B. Ragan-Kelley, F. Pérez, B. Granger, M. Bussonnier, J. Frederic, K. Kelley, J. 738 Hamrick, J. Grout, S. Corlay, P. Ivanov, D. Avila, S. Abdalla, and C. Willing. 2016. Jupyter 739 notebooks - a publishing format for reproducible computational workflows. IOS Press.

740 Kuehne, L. M., and A. L. Strecker, and J. D. Olden. 2019. Knowledge exchange and social 741 capital for freshwater ecosystem assessments. BioScience 70:174-183.

742 Kuehne, L. M., J. D. Olden, A. L. Strecker, J. J. Lawler, and D. M. Theobald. 2017. Past,

743

744

745

746

747

748

749

750

751

752

753

754

755

756

757

758

759

760

761

762

763

764

765

766

767 present, and future of ecological integrity assessment for fresh waters. Frontiers in Ecology and the Environment 15:197-205.

Laan, J. J. V., and C. P. Hawkins. 2014. Enhancing the performance and interpretation of freshwater biological indices: An application in arid zone streams. Ecological Indicators 36:470482.

Lai, J., C. J. Lortie, R. A. Muenchen, J. Yang, and K. Ma. 2019. Evaluating the popularity of R in ecology. Ecosphere 10:e2567.

Landman, A., and S. A. Glantz. 2009. Tobacco industry efforts to undermine policy-relevant research. American Journal of Public Health 99:45-58.

Lenat, D. R., and V. H. Resh. 2001. Taxonomy and stream ecology - the benefits of genus- and species-level identifications. Journal of the North American Benthological Society 20:287-298.

Lewandowsky, S., and D. Bishop. 2016. Research integrity: Don't let transparency damage science. Nature 529:459-461.

Liaw, A., and M. Wiener. 2002. Classification and regression by randomForest. R News 2:1822.

Liu, Y., H. Gupta, E. Springer, and T. Wagener. 2008. Linking science with environmental decision making: Experiences from an integrated modeling approach to supporting sustainable water resources management. Environmental Modelling \& Software 23:846-858.

Lortie, C. J. 2014. Formalized synthesis opportunities for ecology: Systematic reviews and metaanalyses. OIKOS 123:897-902.

Lowndes, J. S. S., B. D. Best, C. Scarborough, J. C. Afflerbach, M. R. Frazier, C. C. O’Hara, N. Jiang, and B. S. Halpern. 2017. Our path to better science in less time using open data science tools. Nature Ecology \& Evolution 1:1-7.

Makel, M. C., J. A. Plucker, and B. Hegarty. 2012. Replications in psychology research: How often do they really occur? Perspectives on Psychological Science 7:537-542.

768 Marwick, B., J. d'Alpoim Guedes, C. M. Barton, L. A. Bates, M. Baxter, A. Bevan, E. A.

769 Bollwerk, R. K. Bocinsky, T. Brughmans, A. K. Carter, C. Conrad, D. A. Contreras, S. Costa, E.

770 R. Crema, A. Daggett, B. Davies, B. L. Drake, T. S. Dye, P. France, R. Fullagar, D. Giusti, S.

771 Graham, M. D. Harris, J. Hawks, S. Heath, D. Huffer, E. C. Kansa, S. W. Kansa, M. E. Madsen,

772 J. Melcher, J. Negre, F. D. Neiman, R. Opitz, D. C. Orton, P. Przystupa, M. Raviele, J. Riel-

773 Salvatore, P. Riris, I. Romanowska, N. Strupler, I. I. Ullah, H. G. V. Vlack, E. C. Watrall, C. 
774 Webster, J. Wells, J. Winters, and C. D. Wren. 2016. Open science in archaeology. SAA

775 Archaeological Record 17:8-14.

776 Mazor, R. D., A. C. Rehn, P. R. Ode, M. Engeln, K. C. Schiff, E. D. Stein, D. J. Gillett, D. B.

777 Herbst, and C. P. Hawkins. 2016. Bioassessment in complex environments: Designing an index

778 for consistent meaning in different settings. Freshwater Science 35:249-271.

779 Mazor, R. D., E. D. Stein, P. R. Ode, and K. Schiff. 2014. Integrating intermittent streams into

780 watershed assessments: Applicability of an index of biotic integrity. Freshwater Science 35:459-

781474.

782 McKay, L., T. Bondelid, T. Dewald, J. Johnston, R. Moore, and A. Reah. 2012. NHDPlus

783 Version 2: User Guide.

784 Michener, W. K., J. W. Brunt, J. J. Helly, T. B. Kirchner, and S. G. Stafford. 1997.

785 Nongeospatial metadata for the ecological sciences. Ecological Applications 7:330-342.

786

787

788

789

790

791

792

793

794

795

796

797

798

799

800

801

802

803

804

805

806

807

808

809

810

Mitchell, B. 2005. Integrated water resource management, institutional arrangements, and land use planning. Environmental Planning A: Economy and Space 37:1335-1352.

Munafó, M. R., B. A. Nosek, D. V. M. Bishop, K. S. Button, C. D. Chambers, N. P. du Sert, U. Simonsohn, E. J. Wagenmakers, J. J. Ware, and J. P. A. Loannidis. 2017. A manifesto for reproducible science. Nature Human Behavior 1.

Nichols, S. J., L. A. Barmuta, B. C. Chessman, P. E. Davies, F. J. Dyer, E. T. Harrison, C. P. Hawkins, I. Jones, B. J. Kefford, S. Linke, R. Marchant, L. Metzeling, K. Moon, R. Ogden, M. Peat, T. B. Reynoldson, and R. M. Thompson. 2016. The imperative need for nationally coordinated bioassessment of rivers and streams. Marine and Freshwater Research 68:599-613.

Nosek, B. A., C. R. Ebersole, A. C. DeHaven, and D. T. Mellor. 2018. The preregistration revolution. Proceedings of the National Academy of Sciences 115:2600-2606.

Ode, P. R., A. C. Rehn, R. D. Mazor, K. C. Schiff, E. D. Stein, J. T. May, L. R. Brown, D. B. Herbst, D. Gillett, K. Lunde, and C. P. Hawkins. 2016. Evaluating the adequacy of a referencesite pool for ecological assessments in environmentally complex regions. Freshwater Science $35: 237-248$.

Oksanen, J., F. G. Blanchet, M. Friendly, R. Kindt, P. Legendre, D. McGlinn, P. R. Minchin, R. B. O'Hara, G. L. Simpson, P. Solymos, M. H. H. Stevens, E. Szoecs, and H. Wagner. 2018. Vegan: Community ecology package. https://CRAN.R-project.org/package=vegan.

Oudenhoven, A. P. E. van, M. Schröter, and R. de Groot. 2016. Open access to science on ecosystem services and biodiversity. International Journal of Biodiversity Science, Ecosystem Services \& Management 12:239-241.

Pebesma, E. 2018. Sf: Simple features for r. https://CRAN.R-project.org/package=sf.

Pilkington, M. 2016. Blockchain technology: Principles and applications. Pages 225-253 in F. X. Olleros and M. Zhegu, editors. Research handbook on digital transformations. Edward Elgar Publishing, Cheltenham, United Kingdom. 
811 Pinheiro, J., D. Bates, S. DebRoy, D. Sarkar, and R Core Team. 2018. nlme: Linear and

812 nonlinear mixed effects models. https://CRAN.R-project.org/package=nlme.

813 Pohjola, M. V., and J. T. Tuomisto. 2011. Openness in participation, assessment, and policy

814 making upon issues of environment and environmental health: A review of literature and recent

815 project results. Environmental Health 10:1-13.

816 Poikane, S., N. Zampoukas, A. Borja, S. P. Davies, W. van de Bund, and S. Birk. 2014.

817 Intercalibration of aquatic ecological assessment methods in the European Union. Environmental

818 Science \& Policy 44:237-246.

819 Powers, S. M., and S. E. Hampton. 2019. Open science, reproducibility, and transparency in

820 ecology. Ecological Applications 29:e01822.

821 RDCT (R Development Core Team). 2018. R: A language and environment for statistical

822 computing, v3.5.1. R Foundation for Statistical Computing, Vienna, Austria.

823 Rehn, A. C., R. D. Mazor, and P. R. Ode. 2018. An index to measure the quality of physical

824 habitat in California wadeable streams. California Water Boards, Surface Water Ambient

825 Monitoring Program, California Department of Fish; Wildlife, Southern California Coastal

826 Water Research Project, Sacramento, California.

827 Slater, L. J., G. Thirel, s. Harrigan, O. Delaigue, A. Hurley, A. Khouakhi, I. Prosdocimi, C.

828 Vitolo, and K. smith. 2019. Using R in hydrology: A review of recent developments and future

829 directions. Hydrology and Earth System Sciences 23:2939-2963.

830 Stein, E. D., M. Brinson, M. C. Rains, W. Kleindl, and F. R. Hauer. 2009. Wetland assessment

831 alphabet soup: How to choose (or not choose) the right assessment method. Society of Wetland

832 Scientists Bulletin 26:20-24.

833 Stevens, S. L. R., M. Kuzak, C. Martinez, A. Moser, P. Bleeker, and M. Galland. 2018. Building

834 a local community of practice in scientific programming for life scientists. PLoS Biology

835 16:e2005561.

836 Stoddard, J. L., D. P. Larsen, C. P. Hawkins, R. K. Johnson, and R. H. Norris. 2006. Setting

837 expectations for the ecological condition of streams: The concept of reference condition.

838 Ecological Applications 16:1267-1276.

839 Taylor, J. M., J. A. Back, B. W. Brooks, and R. S. King. 2018. Spatial, temporal and

840 experimental: Three study design cornerstones for establishing defensible numeric criteria in

841 freshwater ecosystems. Journal of Applied Ecology 55:2114-2123.

842 Taylor, J. M., R. S. King, A. A. Pease, and K. O. Winemiller. 2014. Nonlinear response of

843 stream ecosystem structure to low-level phosphorus enrichment. Freshwater Biology 59:969-

844984.

845 Touchon, J. C., and M. W. McCoy. 2016. The mismatch between current statistical practice and

846 doctoral training in ecology. Ecosphere 7:e01394. 
847 White, B. P., E. M. Pilgrim, L. M. Boykin, E. D. Stein, and R. D. Mazor. 2014. Comparison of

848 four species-delimitation methods applied to a DNA barcode data set of insect larvae for use in

849 routine bioassessment. Freshwater Science 33:338-348.

850 Wickham, H. 2009. Ggplot2: Elegant graphics for data analysis. Springer-Verlag. New York.

851 http://had.co.nz/ggplot2/book

852 Wickham, H. 2015. R packages. Page 182. O’Reilly, Sebastopol, California.

853 Wickham, H. 2017. Tidyverse: Easily install and load the 'tidyverse'. https://CRAN.R-

854 project.org/package=tidyverse

855 Wickham, H., J. Hester, and W. Chang. 2018. Devtools: Tools to make developing r packages 856 easier. https://CRAN.R-project.org/package=devtools

857 Wilkinson, L. 2005. The grammar of graphics. Page 691. Second ed. Statistics; Computing, 858 Springer, New York.

859 Woelfle, M., P. Olliaro, and M. H. Todd. 2011. Open science is a research accelerator. Nature 860 Chemistry 3:745-748.

861 Wood, S. N. 2017. Generalized additive models: An introduction with r. Page 476. 2nd editions. 862 Chapman; Hall, CRC Press, London, United Kingdom.

863 Xie, Y. 2015. Dynamic documents with R and knitr. 2nd editions. Chapman; Hall/CRC, Boca 864 Raton, Florida.

865 Yenni, G. M., E. M. Christensen, E. K. Bledsoe, S. R. Supp, R. M. Diaz, E. P. White, and s. K. 866 M. Ernest. 2019. Developing a modern data workflow for regularly updated data. PLoS Biology 867 17:e3000125.

868 Yuan, L. L. 2004. Assigning macroinvertebrate tolerance classifications using generalised 869 additive models. Freshwater Biology 49:662-677.

870 Zipper, S. C., K. S. S. Whitney, J. M. Deines, K. M. Befus, U. Bhatia, S. J. Albers, J. Beecher, C. 871 Brelsford, M. Garcia, T. Gleeson, F. O’Donnell, D. Resnik, and E. Schlager. 2019. Balancing

872 open science and data privacy in the water sciences. Water Resources Research 55:1-10. 
Figure 1

A simplified workflow of the open science paradigm (adapted from Hampton et al. 2015).

All aspects of the research process, from the conception of an idea to publishing a product, can be enhanced using open science tools. The workflow is iterative where products are continually improved through collaborations facilitated through discovery and reproducibility of open data.

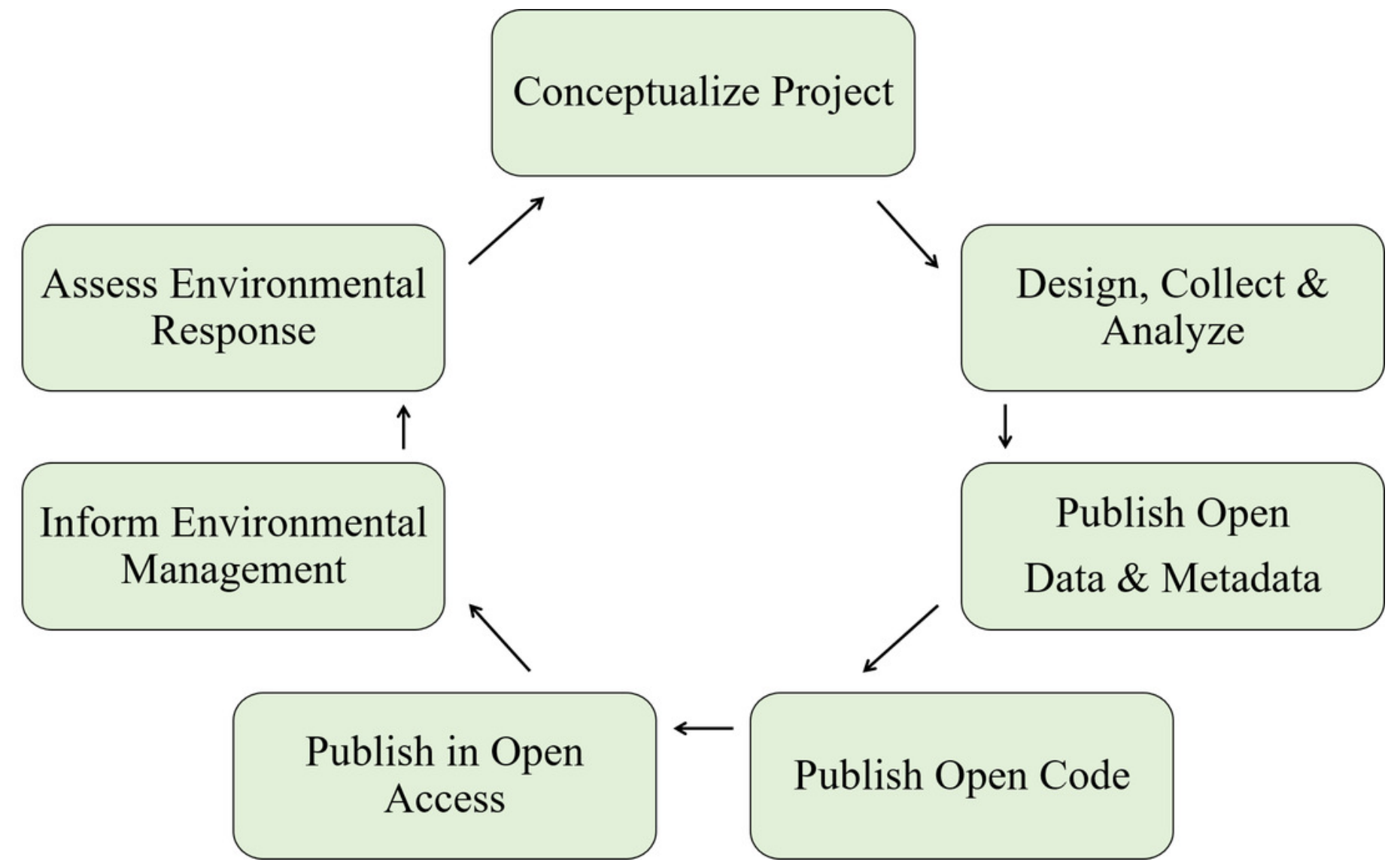




\section{Figure 2}

An idealized open approach for bioassessment applications.

The green box represents the technical steps of the individual research team for developing the product, the manager and stakeholder box are those that require or motivate the creation of bioassessment products, the gray boxes indicate sources of external information (data and guidance documents) as input into the technical process, and the open text indicates open components of the planning, application, or implementation phase of a bioassessment product. Figures were adapted from Hampton et al. (2015). NGO: nongovernment organization, RMP: regional monitoring program. 


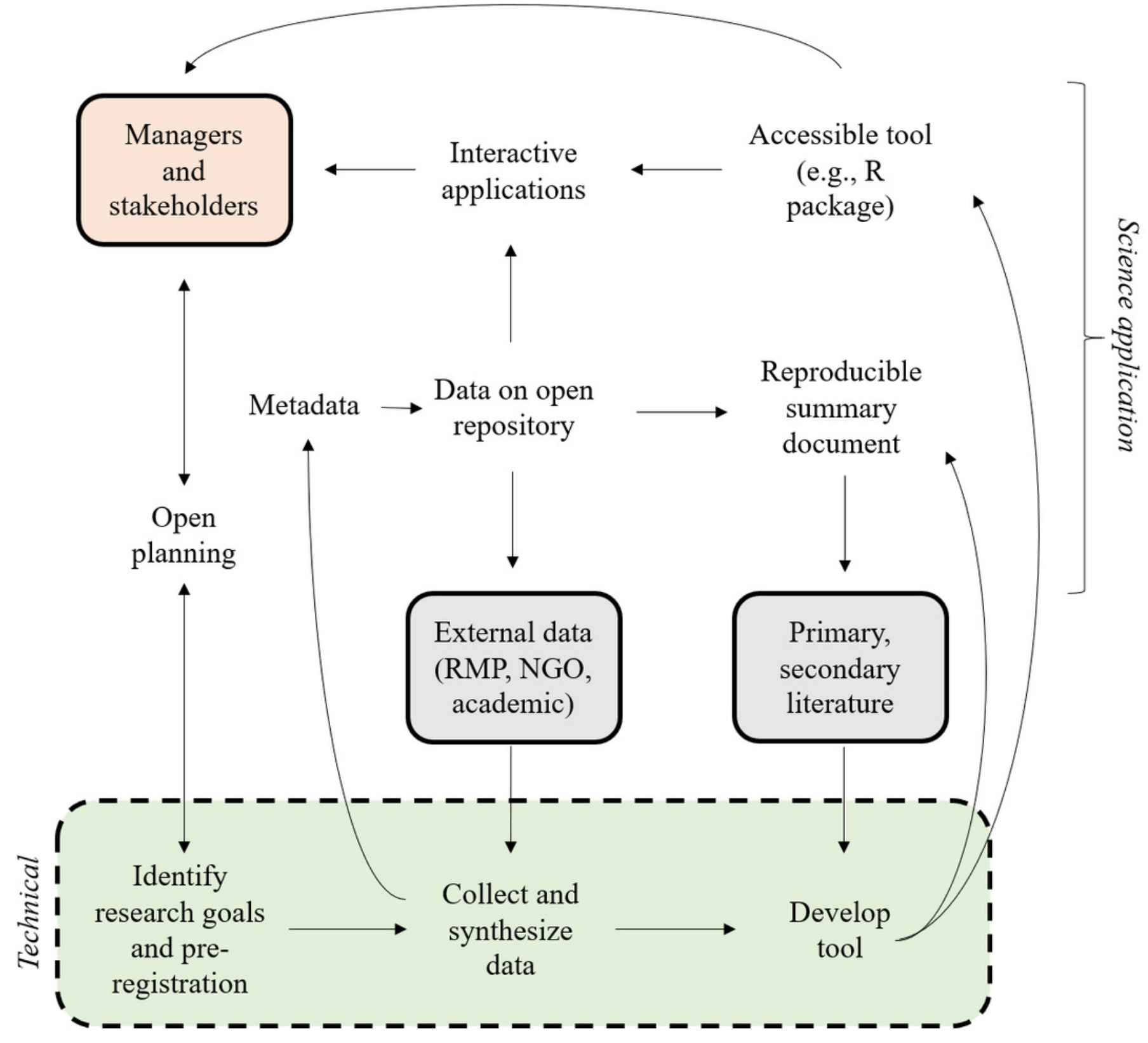




\section{Figure 3}

Schematic demonstrating how the Stream Classification and Community Explorer (SCAPE) can be used to identify potential management actions for stream sites.

Stream segment classifications are defined as biologically constrained or unconstrained based on landscape characteristics (A) and sites with bioassessment scores are evaluated relative to the classifications. Sites can be under-scoring, as expected, or over-scoring relative to the segment classification and expected range of scores (middle plot). Unconstrained sites are those where present landscape conditions do not limit biological potential and constrained sites are those where landscape conditions limit biological potential (B). Management actions and priorities can be defined based on site scores relative to segment classifications. TMDL: Total Maximum Daily Load. Photo credit: Raphael Mazor. 
Site score

$\nabla$ under scoring

A
Segment class

likely constrained $=$ possibly unconstrained

possibly constrained $=$ likely unconstrained

B
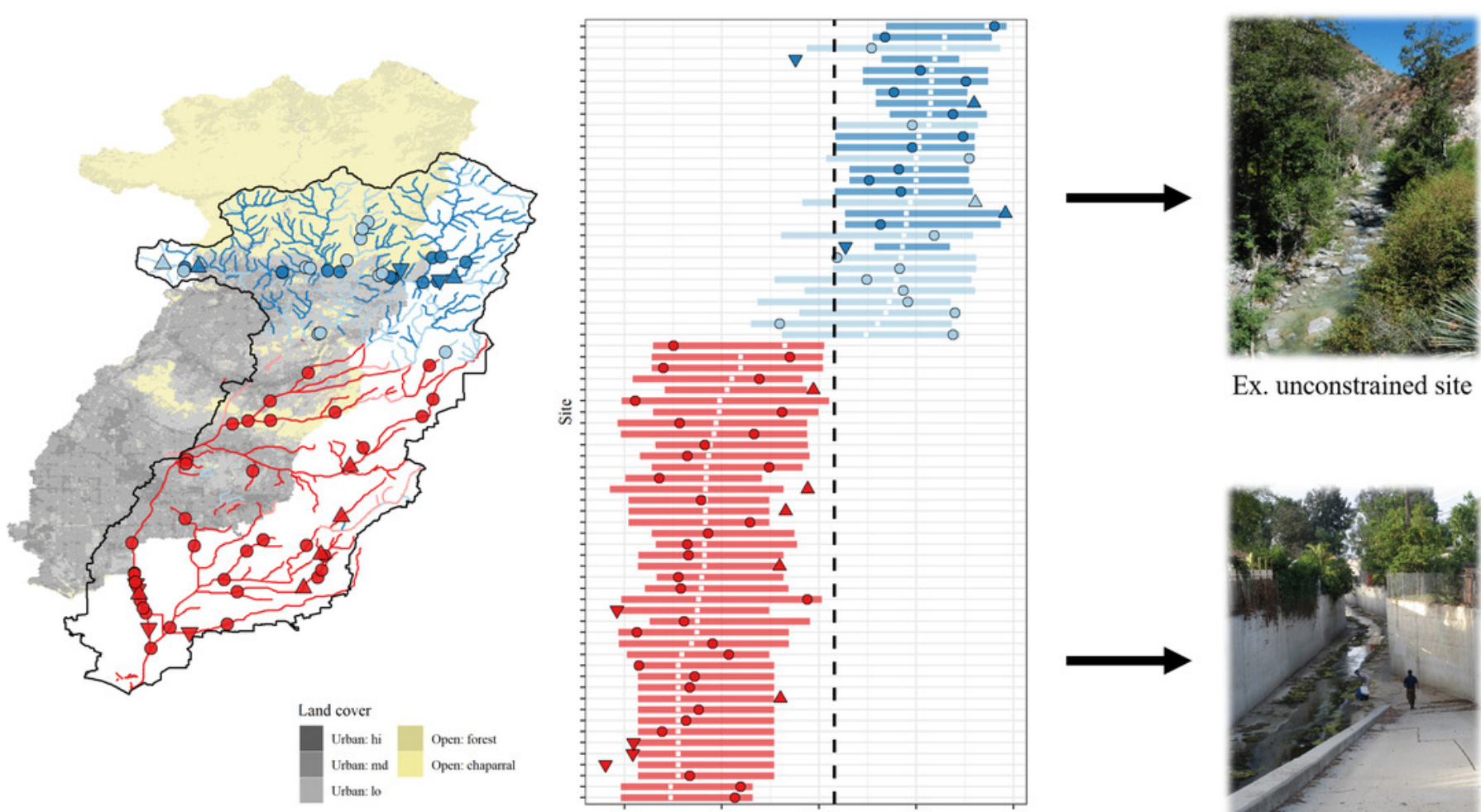

Ex. unconstrained site
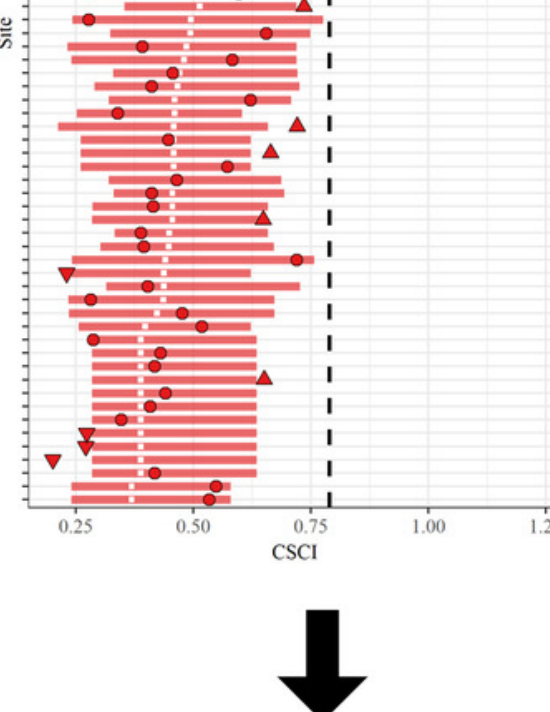

Example high priority site

Action

Example activity

Investigate Higher frequency of sampling, evaluate additional data (e.g., habitat)

Protect

Extra scrutiny of proposed impacts

Restore

Make funding recommendations, prioritize TMDL development
Sites scoring outside prediction interval

Unconstrained sites

Low-scoring unconstrained sites
Example low priority site

Constrained sites

Low-scoring constrained sites
Sites scoring as expected 


\section{Table $\mathbf{1}$ (on next page)}

Core definitions and principles of open science.

Content adapted from Open Knowledge International, http://opendefiniion.org/ , Creative Commons, https://creativecommons.org/about/program-areas/open-science/ , D. Gezelter, http://openscience.org/, and Powers and Hampton (2019). 
Concepts and

principles Description

Open Anyone can freely access, use, modify, and share for any purpose

Open Science Practicing science in such a way that others can collaborate and contribute, where research data, lab notes and other research processes are freely available, under terms that enable reuse, redistribution and reproduction of the research and its underlying data and methods

Reproducible Producing equivalent outcomes from the same data set, or in the case of computational reproducibility, producing equivalent outcomes from the same data set using the same code and software as the original study

Principle 1 Transparency in experimental methods, observations, and collection of data

Principle $2 \quad$ Public availability and reusability of scientific data

Principle 3 Public accessibility and transparency of scientific communication

Principle 4 The use of web-based tools to facilitate scientific collaboration and reproducibility 


\section{Table 2 (on next page)}

$\mathrm{R}$ packages that can be used in the development and application of bioassessment products. 


\begin{tabular}{|c|c|c|}
\hline Task & Package & Description \\
\hline General & $\begin{array}{l}\text { tidyverse (Wickham } \\
\text { 2017) }\end{array}$ & $\begin{array}{l}\text { A suite of packages to import, wrangle, } \\
\text { explore, and plot data. Includes the popular } \\
\text { ggplot } 2 \text { and dplyr packages. }\end{array}$ \\
\hline \multirow[t]{4}{*}{$\begin{array}{l}\text { Mapping, } \\
\text { geospatial }\end{array}$} & sf (Pebesma 2018) & $\begin{array}{l}\text { A simple features architecture for working } \\
\text { with vectorized spatial data, including } \\
\text { common geospatial analysis functions }\end{array}$ \\
\hline & raster (Hijmans 2019) & $\begin{array}{l}\text { Reading, writing, manipulating, analyzing, } \\
\text { and modeling gridded spatial data }\end{array}$ \\
\hline & $\begin{array}{l}\text { leaflet (Cheng et } \\
\text { al. 2018) }\end{array}$ & $\begin{array}{l}\text { Integration of R with the popular JavaScript } \\
\text { leaflet library for interactive maps }\end{array}$ \\
\hline & $\begin{array}{l}\text { mapview (Appelhans et } \\
\text { al. 2018) }\end{array}$ & $\begin{array}{l}\text { Creates interactive maps to quickly examine } \\
\text { and visually investigate spatial data, built off } \\
\text { leaflet and integrated with sf }\end{array}$ \\
\hline \multirow[t]{3}{*}{$\begin{array}{l}\text { Statistical } \\
\text { modeling }\end{array}$} & $\begin{array}{l}\text { randomForest (Liaw } \\
\text { and Wiener 2002) }\end{array}$ & $\begin{array}{l}\text { Create classification and regression trees for } \\
\text { predictive modeling }\end{array}$ \\
\hline & $\begin{array}{l}\text { nlme (Pinheiro et } \\
\text { al. 2018) }\end{array}$ & Non-linear, mixed effects modeling \\
\hline & mgcv (Wood 2017) & Generalized additive modeling \\
\hline \multirow[t]{3}{*}{$\begin{array}{l}\text { Community } \\
\text { analysis }\end{array}$} & $\begin{array}{l}\text { TITAN2 (Baker et } \\
\text { al. 2015) }\end{array}$ & $\begin{array}{l}\text { Ecological community threshold analysis } \\
\text { using indicator species scores }\end{array}$ \\
\hline & $\begin{array}{l}\text { indicspecies (De } \\
\text { Caceres and Legendre } \\
\text { 2009) }\end{array}$ & Indicator species analysis \\
\hline & $\begin{array}{l}\text { vegan (Oksanen et } \\
\text { al. 2018) }\end{array}$ & Multivariate analysis for community ecology \\
\hline \multirow[t]{3}{*}{$\begin{array}{l}\text { Science } \\
\text { communication }\end{array}$} & $\begin{array}{l}\text { shiny (Chang et } \\
\text { al. 2018) }\end{array}$ & $\begin{array}{l}\text { Reactive programming tools to create } \\
\text { interactive and customizable web applications }\end{array}$ \\
\hline & $\begin{array}{l}\text { rmarkdown (Allaire et } \\
\text { al. 2018) }\end{array}$ & $\begin{array}{l}\text { Tools for working with markdown markup } \\
\text { languages in .Rmd files }\end{array}$ \\
\hline & knitr (Xie 2015) & $\begin{array}{l}\text { Automated tools for markdown files that } \\
\text { process integrated R code chunks }\end{array}$ \\
\hline
\end{tabular}

